\title{
ÁLVARO CUNQUEIRO Y EL FETICHISMO SENTIMENTAL
}

Alberto Moreiras

Texas A\&M University

doi:10.17075/mucnoc.2014.006 

Forcadela, M. / T. López / D. Vilavedra (coords.) (2014): Mil e un cunqueiros. Novas olladas para un centenario, Santiago de Compostela, Consello da Cultura Galega. doi:10.17075/mucnoc.2014. pp. 139-156

\section{I.}

En un libro reciente, Pensiero vivente, el filósofo italiano Roberto Esposito se refiere a un nuevo registro tonal o tonalidad común en el pensamiento contemporáneo que tendría que ver con el agotamiento del viejo giro lingüístico y el surgimiento tendencial de una nueva modalidad del pensamiento que afirmaría resueltamente la vida como su propio horizonte. Para Esposito, tal desplazamiento paradigmático sucede de forma más clara no por casualidad en el pensamiento italiano contemporáneo, porque el pensamiento italiano habría permanecido resueltamente al margen del llamado giro lingüístico. La lengua nunca constituyó en Italia el horizonte trascendental del pensamiento, y así Italia estaría en mejor posición que otras tradiciones filosóficas para abrazar una nueva temática a caballo entre vida, historia y política, que desde la tradición italiana permite desbancar los otros dos grandes horizontes trascendentales del pensamiento moderno: el trabajo o el lenguaje.

Se me ocurre que Álvaro Cunqueiro estaría en principio de acuerdo con la noción de que la vida, y no el trabajo (entendido como la condición material de la existencia social) ni el lenguaje, ha de ser el horizonte trascendental del pensamiento. Para mí, que empecé a leer a Cunqueiro en la adolescencia, fue siempre difícil situar su obra dentro de las tendencias críticas que han dominado el discurso académico en los últimos treinta o cuarenta años y que han estado, efectivamente, siempre hipotecadas, bien al servicio de un pensamiento del trabajo (el marxismo es la más obvia), bien al servicio de una reflexión metalingüística que se ha resuelto, en última instancia, en negatividad crítica. Ni puede fácilmente leerse a Cunqueiro desde la intersección trabajo/lenguaje que ha marcado los últimos veinte o treinta años de reflexión sobre la cultura. Cunqueiro no es, por ejemplo, primariamente un novelista de la alegoría nacional, no es un novelista de los grandes movimientos sociales y no es un novelista de la trinidad raza-sexo-género. Poco sentido tenía, en mi opinión, hacer una lectura marxista o deconstructiva de Cunqueiro y poco sentido sigue teniendo hacer una lectura culturalista de su 
obra. Pero también otros intentos provenientes de paradigmas críticos más antiguos, como el de sujetarlo a análisis semiótico, han dado pocos frutos. Quizás Cunqueiro es un escritor cuya escritura es difícil de abordar críticamente, y así un escritor sobre el que resulta difícil escribir. Esto es curioso. ¿Por qué? Con Cunqueiro uno siempre arriesga a quedarse en la glosa del aparato literario o el comentario edificador, sea a favor del melodrama popular en ciertas obras o a favor de la ensońación imaginativa, creadora o recreadora de mundos evocados aunque raramente evocables. La literatura de Cunqueiro tiende a pasmar o a maravillar, pero es pocas veces productiva de genuino pensamiento crítico. Ahora bien, nunca sabremos si este es propiamente un problema de la literatura de Cunqueiro o es más bien un problema de lo que se da en llamar pensamiento crítico.

Voy a sugerir una hipótesis crítica cuyo éxito podrá parecer más o menos acertado para algunas de sus obras, quizás no aplicable a otras. Mi hipótesis debe quizá incluirse en el interés por desarrollar categorías críticas respecto a ese nuevo registro tonal de la vida que anuncia o certifica Esposito. El mismo Cunqueiro se pregunta en un lugar crucial de Un hombre que se parecía a Oreste (1968): "iA qué llaman los hombres vivir?» (127). Pensar la vida desde la vida es difícil y el peligro de la ingenuidad es siempre abismal. Esa misma frase aparece en el texto cunqueiriano en el momento en que Egisto, cuya inmensa melancolía en la espera del destino apenas recibe alivio, encuentra un breve respiro de libertad: «Desde los años de mocedad, nunca Egisto se había visto solo en el campo, saludado por el sol, libre cabalgador. Cantaban los pájaros en los alisos, volaban los cuervos en los barbechos y sobre su cabeza describía anchos círculos, indolente cazador de gazapos, el gavilán. ¿A qué llaman los hombres vivir?» (127). Pero la vida, sabemos, no es la euforia de un paseo a caballo por el campo.

En otro de sus libros, Las mocedades de Ulises, de 1960, la pregunta por la vida es inaugural. «Buscar el secreto profundo de la vida es el grande, nobilísimo ocio» nos dice su primera página. Aprender a vivir, nos dice el Cunqueiro de 1960, constituye un «largo aprendizaje —el aprendizaje del oficio de hombre—, sin duda difícil» (7). Y Cunqueiro acompaña su breve prólogo con una declaración abiertamente ideológica a la que tendremos que volver más tarde: «Toda novedad y toda primavera penden del corazón del hombre y es éste quien elige las estaciones, las ardientes amistades, las canciones, los caminos, la esposa y la sepultura, también las soledades, los naufragios y las derrotas» (7). ¿Elegimos? ¿Qué garanti- 
za, en la vida humana, tan potente capacidad de elección? ¿O se trata más bien de aprender a elegir, en un proceso abierto en el que todo lo que pasa pueda hacerse afirmativo a través de la elección? Aprender a decir sí, en otras palabras, en una formulación que podría pretenderse decididamente nietzscheana, excepto que, en la misma página, ese proceso de libre elección queda vinculado al retorno a Itaca y al encuentro con «el rostro de la eterna nostalgia» (7).

Aprender el oficio de vivir, buscar el secreto profundo de la vida, es regresar a casa - Itaca es el dolor del retorno, pero en tal nostos se consuma la libertad creativa de lo humano. "Todo regreso de un hombre a Itaca es otra creación del mundo» (7). La literatura aparece así como consumación del nostos. ¿Estamos preparados a aceptar tal definición? ¿Podemos admitir que la vida, entendida como proceso de libre elección de eventos, de libre afirmación de lo que pasa, tiene como meta el retorno entrópico a su propio origen? Es como si el conatus essendi spinoziano debiera transmutarse en un conatus primi essendi; como si todo lo hecho en el camino de la vida debiera cabalmente hacerse para deshacer lo andado.

Permítanme entrar rápidamente en materia. Lo haré refiriéndome al artículo de Sigmund Freud de 1927 titulado «Fetichismo», que es el texto central de las investigaciones de Freud sobre el fetichismo (los otros dos son Tres ensayos sobre la teoría de la sexualidad, de 1905, y "La partición del ego en el proceso de defensa», de 1938). Me apresuro a decir que no es, por supuesto, mi intención diagnosticar a Don Álvaro de fetichista de ninguna forma personal. Sólo quiero sugerir que su literatura, o al menos algunos segmentos significativos de su literatura, tienen semejanzas estructurales con la lógica que Freud identifica, en 1905, 1927 y 1938, como lógica fetichista. Y propondría también que la forma narrativa fetichista es una forma narrativa marginal y transversal a las grandes lógicas narrativas del siglo xx y, por ende, particularmente interesante. Nos faltan en realidad todavía categorías de clasificación de lógicas narrativas, lo que propongo es una modesta contribución a tal empresa.

Para Freud, como se sabe, el fetichismo es un fenómeno psíquico intensamente masculino, aunque su objeto sea quizá negar la diferencia sexual misma y así buscar indiferenciación. La lógica del fetiche es complicada. El niño siente el pánico de la ausencia de pene en la madre como pánico de castración. Si mamá no tiene pene, yo también podría no tenerlo, es decir, podrían cortármelo si no 
me lo han cortado ya. La inversión libidinal fetichista no es, en última instancia, más que el proceso psíquico que asegura una compensación sustitutiva del pene materno, y así la posibilidad apotropaica de superar el pánico a la castración. El ego se parte entre lo que es obvio, que es la constatación de que no hay pene allí, y la afirmación inconsciente de que mamá, o las mujeres, también tienen pene, y ese pene puede ser, por metonimia, un zapato de tacón alto, una liga, una enagua, un delantal. A partir de ese momento, esos objetos quedan dotados con capacidad mágica o fetichista: son capaces de provocar intensa excitación sexual aunque en sí no sean objetos sexuales. Esa intensa excitación sexual, a la vez, constituye una declaración de hostilidad hacia la diferencia sexual misma — no hay diferencia, somos todos iguales. $\mathrm{Y}$ es sobre esa igualdad que se proyecta la posibilidad de recuperación de la madre como objeto parcial, es decir, el acceso eterno al seno materno, «el rostro de la eterna nostalgia», que, sin embargo, sólo queda logrado en el rechazo de la genitalidad femenina real, que produce aversión y horror. De ahí la ambivalencia del fetiche, que, en un mismo gesto de inversión anímica, puede ser abiertamente odiado y, sin embargo, concentrar aura libidinosa en el grado más fuerte.

En un cierto momento de su breve ensayo, dice Freud, un tanto enigmáticamente, que el pánico de la castración no está confinado a la infancia. «En la vida posterior, los hombres adultos pueden experimentar un pánico similar, quizás cuando se oye el grito de que el trono y el altar están en peligro, y a ello le siguen también consecuencias ilógicas» (162). Freud no elabora tal frase, pero de ella puede deducirse una extrapolación política al fenómeno fetichista: el fetichismo tiene, efectivamente, quizá inevitablemente, carácter reaccionario. Debemos hacer, por tanto, explícita la pregunta sobre el signo político de la noción de que toda literatura es consumación del nostos. Otra forma de decirlo es suponer que, si toda la literatura es consumación del nostos, toda la literatura es el intento de restitución soberana del trono y del altar, o bien, para ponerlo en términos que podría haber suscrito Carl Schmitt, todo concepto literario es secularización de un concepto teológico. Hay literatura teológico-política, o más bien la literatura es teológico-política. Parecen palabras excesivas y estamos muy lejos de saber si podrían aplicarse realmente a la literatura de Álvaro Cunqueiro. Pero en todo caso, antes de volver sobre ello al fin de este trabajo, permítanme ofrecerles $\mathrm{mi}$ 
hipótesis: la literatura de Álvaro Cunqueiro es primariamente fetichismo sentimental.

¿Cómo es posible llegar a tal conclusión a partir de la noción de que el secreto más profundo de la vida debe encontrarse en la libre elección del retorno a casa? O, más bien, ¿cómo es posible no llegar a ella? En la teoría psicoanalítica del fetichismo, entendemos que es condición de tal retorno el rechazo de la diferenciación sexual y una ambivalencia constitutiva respecto del estatuto de lo femenino, que debe ser apropiado en su indiferenciación misma. Es como si el trono y el altar fueran en realidad, no poderosos símbolos de la masculinidad dominante en la historia, sino más bien versiones del falo materno, y en esa medida producto de la fantasía masculina. La estrella Libredón guía el camino al seno materno a través del fetiche mismo, a través del gozo fetichista. La sentimentalización del fetiche - en cierto sentido, su rescate con respecto de la oscura energía sexual, su idealización y purificación- es el proceso literario mismo. Pero ¿̨no es esto lo que el joven Karl Marx llamaba «la religión del deseo sensible»? Volveremos a ello.

\section{II.}

En su análisis, no de la historia de Ulises, sino de la Ilíada, de 1940, año de guerra, Simone Weil propone una lectura del gran poema homérico que podría resultarnos útil para entender lo que está en juego en la obra de Cunqueiro. Para Weil no hay nada más grande en la historia del espíritu humano que la Ilíada, y esto es así porque el poeta acierta a expresar el horror de la guerra, el horror del destino de destrucción y de mutua destrucción al que los humanos parecemos estar apegados, sin sancionarlo en ningún momento. La guerra es principio o suelo ontológico en la Ilíada y, sin embargo, la guerra no se confunde con la totalidad de lo real. Para Weil «el verdadero héroe, el verdadero sujeto es la fuerza» (163). No es una fuerza personal, sino aquello impersonal bajo cuyo impacto los hombres viven y mueren en cada caso. La fuerza no es sólo impersonal, sino que despersonaliza y transforma lo humano en cosa, en el límite en esa cosa llamada cadáver, pero antes del límite, más acá de la línea, la fuerza despersonaliza en el sentido de que "puede matar, en cualquier momento, esto es, en todo momento» (165). Nadie en la Ilíada está libre de esa fuerza que engloba la acción y la totali- 
dad de la acción para aqueos y troyanos: «La raza humana no está dividida, en la Ilíada, entre conquistados, esclavos, suplicantes por un lado y conquistadores y jefes por el otro. En este poema, no hay un solo hombre que no tenga que doblegar su cuello ante la fuerza en un momento u otro» (171). La hybris del que está momentáneamente en situación de imponer su fuerza operará retribución y esa bybris es tan inescapable como la fuerza misma, pues es la fuerza misma. «Tal es la naturaleza de la fuerza. Su poder de convertir un hombre en una cosa es doble y de doble filo en su aplicación. En el mismo grado, aunque de diferentes maneras, los que la usan y los que la padecen se convierten en piedra» (184).

Weil habla de la petrificación general de lo humano bajo el impulso de la fuerza, habla de la guerra como condición esencial y suelo ontológico en la Ilíada, pero menciona también la posibilidad de la excepción. «El alma que ha entrado en la provincia de la fuerza no escapará excepto por milagro. Y tales milagros son raros y de duración breve» (185). La Ilíada menciona tales momentos de gracia como amor, hospitalidad, amistad. Son los momentos que la violencia mata y matará siempre, y con respecto de los cuales se desarrolla en el poema, dice Weil, una amargura (188) que constituye la verdad misma de la Iliada como producción del espíritu. «Lo que no es guerra, lo que la guerra destruye o amenaza, la Ilíada envuelve en poesía. Las realidades de la guerra, nunca» (190). Por eso "este poema es un milagro. Su amargura es la sola amargura justificable, pues sale de la sujeción del espíritu humano a la fuerza, esto es, en último análisis, a la materia. Quienquiera que escape del dominio de la fuerza es amado, pero amado con pena dada la amenaza de destrucción que pesa sobre él» (191).

Conviene pensar si la literatura como milagro y excepción a la fuerza, como des-petrificación, si la literatura como gracia y sustracción ontológica, puede reconciliarse con la literatura como encuentro con el rostro eterno de la nostalgia. La lógica del fetiche puede una vez más hacerse útil. En efecto, el trauma de la castración es el despertar inaugural a la realidad de la fuerza o a la fuerza en cuanto real. La lógica fetichista no desmiente la fuerza como real, sino que se adapta a ella encontrando la forma de canalizar la libido como excepción al horror. No es una excepción limpia: sabemos que el fetichismo es ambivalente y que puede encerrar fuertes dosis de agresividad narcisista con respecto de su elección de objeto. Sin embargo, en y mediante su elección de objeto, el fetichismo salva de o resuelve, de alguna difícil manera, la necesidad de la fijeza, de la petrificación, de 
la cosificación que lo real conlleva. ¿No es esto lo que está en juego en la elección cunqueiriana: «Toda novedad y toda primavera penden del corazón del hombre, y es éste quien elige?». La elección cunqueiriana no es una elección en el sendero de una libertad incondicionada, sino que tiene un carácter de decisión, de apuesta, de inversión libidinosa a favor de aquello que salva del horror de lo real. Es también, por lo tanto, literatura amarga. En Las mocedades de Ulises, cuando el pequeño aprende a disparar flechas bajo la tutela del tabernero Poliades, una de las flechas imaginarias silba hacia el afuera y Poliades le dice cruelmente: «iEsa flecha, Ulises, llegó al mar! No dudo que ha encontrado en su camino el sucio cuello de un pirata tuerto. ¡Que Poseidón juegue con sus naves a la pelota!» (76). Ulises le pregunta entonces a Poliades: «Poliades, ¿qué es lo que es mentira?».Y Poliades responde: "Todo lo que no se sueña» (76). El sueño de la verdad es la elaboración apotropaica de una inversión de objeto contra la mentira de lo real. La verdad es sueńo porque es primariamente voluntad de excepción, apertura al milagro de la gracia. Hay amargura y resentimiento ante la vida aquí, sin duda, pero bajo el signo de una ambivalencia radical que desmonta cualquier pretensión de interpretación unilateral. Cunqueiro no tiene nada que ver con el héroe nietzscheano de la afirmación vital incondicionada, pero tampoco con su criatura del resentimiento, con su último hombre. El fetichismo sentimental proyecta su amargura misma como capacidad y potencia de felicidad.

La ambivalencia de la lógica fetichista aparece nítidamente expuesta en uno de los últimos episodios de Mocedades, que es el momento en que Ulises, en Paros, es llevado por Zenón a casa de la señora Alicia con la idea de contratar alojamiento y Ulises, por ninguna razón aparente excepto su voluntad de fabulación, le cuenta a la señora Alicia una historia falsa sobre su propia identidad. Ulises se autopresenta como Dionís de Albania a una Alicia que «vacilaba entre entregarse a los infantiles recuerdos, poco a poco vestidos, en los horizontes de la memoria, con encantadores resplandores, o en acudir presurosa con la final dosis de aceite a la lámpara desasosegada de los deseos, por últimos alocados y vehementes» (205). Ulises entra en un afecto perverso: «le divertía angustiar a aquella manzana madura de la que venía tan cálido perfume de claveles» (206). La historia que le cuenta incluye un gran duque de Constantinopla que trata de seducir a una joven albanesa de quince años que, por casualidad, ha descubierto el secreto de que la barba de monseńor es falsa y postiza. La historia de la barba es más bien extraor- 
dinaria. El gran duque don Galaor perdió la suya propia al fuego de una alquitara de aguardiente, y el Basileo aprobó su reemplazo por una postiza siracusana. En palabras de Cunqueiro, "Al de Siracusa se la sacaron los barberos del Emperador por pegamento, que es invento romano. Gritaba, pero en sacando el bigote, que ha de hacerse en vivo, lo abreviaron, que era un hombre flaco y se dolía mucho. Los barberos creían que las barbas eran para una imagen nueva de San Gregorio Nacianceno, y por su cuenta le pusieron en el revés del mostacho unas plaquitas de plata con sus nombres» (208-09). Don Galaor le deja ver a la muchacha los nombres de los barberos asesinos en un párrafo en el que la barba del gran duque literaliza su posición de falo desplazado y entra en la lógica explícita del fetiche:

Y el gran duque se quitó la barba y le permitió a mi madre que viese las plaquitas y que la acariciase, y era como acariciar, aquella virgen, por vez primera, una hermosa barba de varón, y el hinojo regalaba ese aroma que te dije, que de lejos parece beleńo. Aunque la caricia de Ifigenia en la barba fuese en postizo de barbero constantinopolitano, para ella era una caricia carnal, entregarse a luminoso varón a través de un sueńo. Y se entregó. Soy hijo de esa noche y de esa caricia, el Bastardo de Albania, el Secreto Bastardo de Albania. (209).

El falo barbado es en realidad el falo que Ulises ve en los ávidos senos de Alicia. La historia de violación, en las palabras de Ulises, se hace particularmente brutal en sus márgenes, como cuando le cuenta a Alicia que su madre fue expulsada por su vergüenza del hogar paterno, "que era de nobles capitanes de navíos de guerra, y la primera escalera del salón de respeto hecha con dientes arrancados a los más osados de los enemigos» (209). La historia de castración y violación sigue con la noticia de que doña Florentina, la legítima señora de don Galaor, andaba atenta, para matarla, a toda descendencia ilegítima de su marido, así que Ifigenia debe esconder a su hijo y vestirlo con harapos. Pero la venganza de dońa Florentina era imparable:

Un veneno que venía para mí en una naranja confitada, mató a mi madre. Una flecha disparada desde detrás de unos haces de heno, entró mortal por un ojo de mi caballo, equivocando el camino que llevaba a mi cuello. Fueron muertos mis perros y robadas mis espadas infantiles. Dońa Florentina de Italia me había descubierto, y peligraba mi vida. Por aterrarme, dejaban sogas a los pies de mi cama, y las entraba cuando iba a un lecho que ya solamente me conocía insomne. Mi señora tía enloqueció, hallando por 
toda parte, en el suelo, charcos de sangre fresca, y no sabiendo si de verdad era aquella la mía, en la temprana edad y a traición derramada. (211-12).

Es entonces cuando don Galaor muere y dońa Florentina organiza un ejército para matar al bastardo. «Los que se habían puesto por mis súbditos, especialmente las damas y las doncellas que cité, amables lavadoras de mis fatigados pies, dulces bordadoras de pańuelos para mis nocturnas, escondidas lágrimas, pedían muerte misericorde de mi mano. Me la exigían, pero no se la di. Les regalé mi nave y todo el oro para que huyeran con la marca vespertina, y yo quedé en tierra con la desnuda, larga, brillante, bien empuñada espada» (213). Y es ahí, con la mano en la espada que va a confrontar el horror de la mala madre, combate explícitamente fálico, donde, en la mente de un Ulises disfrazado de Dionís de Albania, se produce la doble afirmación de vida y huida, y así la posibilidad misma de un retorno hacia la venganza que haría posible la imposible recuperación de lo propio, entendido ahora como soberanía real: «me entró el sabor de la vida, y la amarga raíz de la venganza la sentí debajo de la lengua. Le dije adiós a Albania y me hice peregrino, algunos, entre los más jóvenes, sueñan con que vuelvo y me mandan con agitada respiración la caricia de su alegría guerrera. Mientras, yo ando mundo. Calzo ese casco que te dije y duermo, haciéndome sufridor de trabajos militares, al aire libre. Estudio la filosofía de la venganza y me educo libremente en el ejemplo de los coronados de la antigüedad» (213-14).

El pequeño soberano, Su Majestad el Yo, busca su paradójica autonomía, lo que podríamos llamar su autorrecuperación, a través de una práctica de venganza mediante la que accedemos a ese «rostro eterno de la nostalgia», Itaca, o la consumación en lo femenino, que es también la destrucción de lo femenino por indiferenciación. Puede entonces producir sorpresa darse cuenta de que buscar el secreto profundo de la vida equivale a elegir el camino de la venganza y que, por lo tanto, la literatura como consumación del nostos incluye o más bien se constituye como abierta pulsión de muerte y voluntad de retorno a la organicidad indistinta. Perseverar en el propio ser es operar venganza con respecto del trauma de la diferenciación originaria, al que alude la teoría psicoanalítica de la castración infantil. Vivir es deshacer la vida.

Espero que no se entienda que estoy interpretando a Cunqueiro. En realidad, todo esto es notoriamente explícito en su texto y, si decirlo parece subversivo o infamiliar, es sólo porque nuestro discurso crítico, enredado en preguntas alterna- 
tivas cuya repetición ha hecho triviales, ha permanecido en gran medida ciego a la literalidad del texto de Cunqueiro y, quizá, todavía permanezca. El fetichismo sentimental de Cunqueiro es militante con respecto de la tematización de un conflicto originario en lo humano que no tiene paliativo alguno - la inversión fetichista no disuelve el conflicto, sino que lo eleva a dimensión ontológica, con respecto de la cual pide una excepción, una huida. Lo sentimental es precisamente esa ruptura prostética con respecto de la ontología — a la que Cunqueiro, ya lo hemos visto, no vacila en llamar no-mentira, esto es, verdad. Excepto que esa mentira que no se sueña no es ni mucho menos lo contrario de ninguna verdad: es pura y simplemente lo real.

Termino esta presentación somera y meramente indicativa de la lógica fetichista en Las mocedades de Ulises tratando de confirmar la autoconciencia cunqueiriana con respecto de su procedimiento mismo, no porque por mi parte padezca de inseguridad en mis propios postulados, sino porque quiero concluir este trabajo en necesariamente breve referencia a El hombre que se parecía a Orestes, segunda y última novela del ciclo griego de Cunqueiro, y en obvia continuidad temática con la primera. En su Orestes, Cunqueiro medita y radicaliza su relación con el fetichismo y su lógica de la venganza, y sienta las bases de una literatura o de una comprensión de lo literario capaz de romper no con el fetiche sentimental, sino cabalmente con su dimensión teológico-política. Debo adelantar que personalmente considero ese tenue - por desapercibido- movimiento cunqueiriano uno de los más grandes logros del pensamiento gallego, o hispánico, del siglo Xx.

Cuando Laertes, padre de Ulises, celebra ritualmente la genealogía paterna de su hijo varón, a quien su padre quiere rey, sus cuñados, los basilios, protestan por la omisión en el relato de la genealogía materna. Pero pronto se nos revela que la hermosa y pálida Euriclea no era una basílida, sino hija adúltera de un forastero. La bastardía materna es síntoma de lo ineluctable o arbitrario de cada origen, de su calidad en todo caso siempre barrada y en entredicho, siempre sustraída a su presencia aparente, y así siempre tocada por la negación. En el texto, el primer encuentro de Ulises con el mar coincide con las primeras señas de la muerte de su madre, descrita en tonos sombríos. Aquí está la descripción, que a mi juicio operativiza en el texto la lógica fetichista en su plena ambivalencia, en cuanto amor de objeto y horror y resentimiento mortal por su pérdida. Debe notarse la extrema tensión simbólica del párrafo: 
Euriclea se sentaba a hilar, en verano en el patio, a la sombra de la higuera, y con los pies al sol, como dejó adverido Hesíodo, y en invierno, en la cocina, con los pies sobre un caneco de barro lleno de arena caliente. Los pies fríos entorpecen las manos de las hilanderas en la rueca y el huso: sólo unas hay que pueden hilar, veloces y silenciosas, con los pies helados: las Parcas. Euriclea era, verdaderamente, Euriclea la pálida. Tosía. La tos la despertaba a la hora del alba, y Euriclea podía ver, en el pañuelo que acercaba a su boca, un hilillo de roja sangre en la saliva. Euriclea era solamente una dulce voz y una tranquila mirada, que se derramaba desde sus ojos claros, alrededor de cuyo suave verdor marino las largas pestańas oscuras semejaban fatigadas filas de finos remos. (52).

Es justamente después de este párrafo que el piloto Foción le dice a Ulises: « ¿Saca la lengua, Ulises, y prueba! ¡Es amarga! ¡Es agua del mar!» (53). La amargura está en relación metonímica con la presencia terminal de la muerte en el cuerpo de la madre, y es el residuo sentimental de la lógica de la venganza. La muerte de la madre es aquello con respecto de lo cual «la nave de las palabras no sirve. Hay que arrastrar la carne por el agua y la arena» (67). Comienza el éxodo de Ulises y, con su éxodo, también su fijación en la necesidad vengativa del retorno. El retorno, como en el original griego, se consuma a través de Penélope, cuya presentación en la novela de Cunqueiro se establece ya en explícita comparación con Euriclea: «Penélope tenía la piel blanca, aunque sonrojaba manzanera en las mejillas. En el invierno montañés, sería tan pálida, sentada al telar, como Euriclea» (230-31). Pero la variación y novedad cunqueiriana consiste en que Penélope no es aquella que espera en Itaca, sino aquella que será esperada en Itaca, indefinidamente, como precio y prenda del retorno - explícito sustituto materno, y así fetiche en sí, marcado libidinosamente por la marca del telar en la mano:

Tenía en su espalda la mano abierta de Penélope. La pequeña y dulce mano estaría oyendo latir su corazón, mirando con las yemas las letras, una a una, de las palabras locas, enamoradas, ardientes, que el mozo estaba inventando. Palabras que al pasar, por el camino de esa mano, del sueño de él a la inmensa expectación de ella, se detenían un instante en la señal que el estribo del telar antiguo había hecho, día a día, en la palma de la paciente tejedora. Y el amor se hizo en aquel mismo instante profundo y puro, y eterno. (240-41).

Ulises regresa a Itaca y debe esperar allí la llegada de Penélope. Espera tanto que parece esperar hasta más allá de la muerte. Pero, al fin, llega Penélope: «Los 
dedos reconocieron los ojos y la boca antes de que pudieran hacerlo los ojos y la boca. Penélope, la tan amada, era amarga. En la memoria de Ulises surgió Foción, mojándole el rostro: ¡Toma, prueba! ¡Es amarga! ¡Es el agua del mar!» (270).

\section{III.}

Pasan ocho años hasta que la reflexión cunqueiriana sobre la lógica de la venganza se radicaliza en Un hombre que se parecía a Orestes. Pero ya Las mocedades de Ulises habían indicado el camino futuro en el largo párrafo dedicado a un Orestes reconocible en cuanto príncipe que retorna, muestra su sello rojo y es saludado por el heraldo, y se descubre amnésico, incapaz de recordar su propio nombre (95). En esa página de Mocedades, inicia Cunqueiro su crítica de la lógica de la venganza, que es el tema central de la novela de 1968, y, en mi opinión, logra operar una vuelta de tuerca decisiva en el aparato literario cunqueiriano. A partir de ella, la literatura no será ya conceptualizable como consumación del nostos, precisamente porque en ella toma lugar el abandono definitivo del intento de restitución soberana de la autonomía de la conciencia, de lo que Freud cifra en la relación privada con el trono y el altar como instancias de soberanía. Orestes renuncia a su soberanía porque renuncia a seguir el paso dictado para él por la lógica de la venganza, que promete soberanía. Pero entonces, ¿qué pasa con el fetichismo sentimental? ¿Debe abandonarse también?

Recordemos lo que decía Simone Weil en relación con procesos de petrificación y cosificación de lo humano impuestos por la fuerza. El fetichismo, como fuerza o como fenómeno generado por la fuerza, es también petrificación de doble filo, porque petrifica al objeto de deseo convirtiéndolo en cosa y opera mediante la literal petrificación misma del sujeto de deseo (erección) (recordemos que para Freud el fetichismo es un fenómeno intensamente masculino). ¿Cabe, pues, concebir un fetichismo despetrificante? Sería un fetichismo operativo en la desfetichización misma, un fetichismo convertido en crítica del fetichismo o un fetichismo irónico. Quizá la literatura de Cunqueiro evolucione propiamente desde el petrificante fetichismo sentimental hacia el despetrificante fetichismo irónico, que se convierte, por lo tanto, en última instancia de referencia y marca genuina de la literatura cunqueiriana. El fetichismo irónico empieza quizá 
a tomar forma como una categoría crítica afirmativa y productiva para un pensamiento de la vida no en oposición a ningún pensamiento de la muerte, sino en relación a esa vida-muerte que es constitutiva de la finitud misma de lo humano. Eso es lo que yo llamaba antes un gran logro del pensamiento cunqueiriano y una contribución neta y poderosamente original al pensamiento y a la práctica artística en tierras hispánicas.

El joven Marx, en el contexto de su crítica de la religión, llamaba al fetichismo «religión del deseo sensible», lo cual es otra forma de decir religión sin religión o religión no político-teológica. No son ni el trono ni el altar los referentes últimos de esa práctica teológico-política, que es, por ende, más bien una práctica de la libertad. «Un rey es un lujo» decía Cunqueiro, "pero un hombre más libre que los demás en un pueblo no es ningún lujo» (Mocedades 44). El proceso de retorno de Orestes a Micenas, en la versión de Cunqueiro, en el que se consuma el abandono de la lógica de la venganza, es el retorno como práctica de libertad y, así, el principio de una literatura democrática. Ni más ni menos. Si la literatura es consumación del nostos, su signo ha cambiado, porque ya no está bajo la invocación primaria de la lógica de la venganza.

Allí estaba, resumido, el asunto Orestes. Sí. Un hombre en la flor de la edad llegaba, por escondidos caminos, a la ciudad. Traía la muerte en la imaginación, que es esta cosechar antes de sembrar, y tantas veces en el soñar había visto los cadáveres en el suelo, en el charco de su propia sangre, que ya nada podría detenerlo. En el pensamiento de Orestes, la espada tendría la naturaleza del rayo. La inmunda pareja real yacía ante él. Durante años y años Orestes avanzó paso a paso, al abrigo de las paredes de los huertos, o a través de los bosques. El oído del rey era el amo del rey. Egisto escuchaba el viento en el olivar, los ratones en el desván, los pasos de hierro de los centinelas, la lechuza en el campanario, las voces y las risas en la plaza, a medianoche. ¿Orestes? A su lado, arrodillada en el frío mármol, su mujer se echaba el largo y negro cabello sobre el rostro. Y sollozaba. (23).

«No se vivía en la ciudad con el miedo» dice el texto (43). Y el miedo produce no sólo miedo, sino también expectación y goce profundos. Se acerca la hora de la venganza y «siempre hay que estar en el partido de los héroes mozos que surgen de las tinieblas con el relámpago de la venganza en la mirada» (25). ¿ ¿Siempre? Esta es la visión del mundo que el fetichismo irónico de Cunqueiro se encargará de destruir en su movimiento 
textual, de nuevo de forma absolutamente lúcida, a la que el texto le da incluso un fuerte tinte anti-hobbesiano y anti-hegeliano. La lógica de la venganza, dice Cunqueiro, es fetichismo de Estado: «la razón de Estado llega a ser maquinal y obra como un fin, creando una realidad propia ante la cual los humanos somos como siervos fantasmas de la gran idea. Se cortan cabezas no porque sean cabezas, es decir, pensamientos capaces de armar un brazo terrible, sino porque las excepciones prueban el argumento soberano» (68-69).

Contra el fetichismo de Estado, contra la petrificación por excelencia, en un primer momento, la crítica de Orestes se hace pragmática y resolutoria: "Orestes se sale de página. Orestes está impaciente. No quiere estar en la página ciento cincuenta esperando a que llegue la hora de la venganza. Se va a adelantar. No quiere perder sus años de mocedad en la espera de la hora propicia. Está cansado de escuchar a Electra. No quiere estar atado de por vida al vaticinio fatal. Y decide ir a buscarte y darte muerte» (98). El pobre Egisto, que todavía no habría matado a Agamenón ni casado con Clitemnestra, se escandaliza. O bien declaramos muerto a Orestes, y ahí se acabó todo también. Si Orestes ya murió, no habrá venganza. Así, aunque sea mentira, "con las dudas, tu vida será diferente. Un hombre que duda es un hombre libre, y el dudoso llega a ser poético soñador, por la necesidad espiritual de certezas, querido colega» (101).

Pero la obra cunqueiriana no opta por ninguna de esas resoluciones ni por resolución alguna. Se limita a constatar que, en el límite, la gran hora de la venganza no puede llegar y que el fetiche nunca encontrará resolución libidinosa. "¿Qué habrá sido de Orestes?, preguntó el propio Orestes con una voz fría y distante, por simple curiosidad. ¿Quién puede responder a esa pregunta sino Orestes?» (227). Pero Orestes, en un principio, no responde. Tiene mucho que pensar. Se ha dado cuenta de algo. «Gruesas lágrimas rodaban por el rostro del príncipe. Nunca, nunca podría vivir en su ciudad natal. Para siempre era una sombra perdida por los caminos» (227). 


\section{REFERENCIAS BIBLIOGRÁFICAS}

Cunqueiro, Álvaro: Las mocedades de Ulises. Barcelona: Destino, 1970.

Cunqueiro, Álvaro: Un hombre que se parecía a Orestes. Barcelona: Destino, 1969.

Esposito, Roberto: Pensiero vivente. Origine e attualitá della filosofia italiana. Turín: Einaudi, 2010.

Freud, Sigmund: «Fetishism». International Journal of Psychoanalysis 9 (1928): 161-66.

PIETz, William: «Fetishism and Materialism: The Limits of Theory in Marx» en Emily Apter y William Pietz eds., Fetishism as Cultural Discourse. Ithaca: Cornell UP, 1993. 119-51.

WeIL, Simone: «The Iliad or the Poem of Force» en Sian Miles ed., Simone Weil: An Anthology. Nueva York: Weidenfeld and Nicolson, 1986. 162-95. 
